\title{
Research on Key Technology of Animation Scene Based on Computer Technology
}

\author{
Guo Xin \\ School of Software Service Outsourcing \\ Jishou University \\ Zhangjiajie, China \\ jianghai079@126.com
}

\begin{abstract}
Animation technology is a involves many disciplines cross technology, with the continuous progress of science and technology, more and more new technology application to the animation technology, the traditional two-dimensional animation has tended to be eliminated, and 3D animation development rapidly, is to dominate the trend in the field of animation, however, the three dimensional animation scene technology is not mature greatly restricts the development of 3D animation, in this context, this paper presents a study method based on the key technology of computer animation, the use of computer technology to create a good animation scene In the $3 D$ animation scene contains interior, exterior, a combination of exterior and interior scenes, secondly some animation scene will have computer stunt to join, and computer simulation. Which interior is mainly in the lives of the characters of buildings and transport of the internal space, location is mainly refers to take the natural landscape scenes. Compared to the characteristics of interior exterior open space for the scene. The exterior and interior scenes together is called the combination of internal and external view. Which is the best of both internal and external, because it allows the role of performing in different space.
\end{abstract}

Keywords- Computer technology; animation scene; key technology; production method; technical analysis

\section{INTRODUCTION}

With the rapid development of computer technology, animation technology has also been a tremendous change ${ }^{[1]}$. An excellent animation work was born, often can not leave the animation scene. The most central part of the creation and production of the animation scene. Designers have to design a satisfactory animation scene must also be a good grasp of the shape, motion control and animation rendering these three important aspects ${ }^{[2]}$. How to model the animation scene, how to ensure that the object in the process of movement will not change, how to complete the animation scene is the difficulty and hot spot ${ }^{[3-4]}$. However, China's animation industry is still in the initial stage of development, for the film and television animation film for the targeted research is also less and less. Although the computer generated is a virtual animation scene, but for these problems, this paper first introduces the key technology of computer animation scene, and now the development of the key technologies of modeling, motion control, scene rendering ${ }^{[4-5]}$.

\section{RESEARCH ON THE SIGNIFICANCE OF ANIMATION SCENES}

China's animation industry is still in the initial stage of development, has not developed into a complete set of animation industry, but Europe and the United States and Japan and South Korea these countries of the animation industry has become a pillar industry in the country, and the proportion of domestic animation industry is negligible ${ }^{[6]}$. Today, globalization and information technology, as soon as possible the development of China's animation is imminent, we must make full use of the current domestic and international animation development environment, grasp the importance of computer technology animation scene, attention to the characteristics of animation scene design, in order to make the majority of the audience can readily accept its extraordinary impact, for China's animation industry to make due contribution $^{[7-8]}$.

\section{STYLE AND CLASSIFICATION OF ANIMATION SCENES}

The role of the animation and the role of the performance of the occasion, as well as the environment known as the animation scene. The design of the animation scene includes the time and space design of the environment. In the 3D animation scene generally combined for the interior, exterior, interior and exterior scenes, computer graphics, combined with the king, computer simulation the six scene ${ }^{[9-10]}$. Which interior is mainly in the lives of the characters of buildings and transport of the internal space, location is mainly refers to take the natural landscape scenes. The location is characterized by relatively open space scene. The combination of internal and external view refers to the exterior and interior scenes together. Which is the best of both internal and external, because it allows the role of performing in different space.

The design of a cartoon scene plays a decisive role in the visual effect of the whole film, and the design of the animation scene style should conform to the requirements of the script theme and characters. The art style of the scene is divided into realistic style, cartoon style and comprehensive experimental style.

Stop-motion animation, also known as frame by frame animation is an animation technique, the principle is about a different image for each frame of continuous playback, resulting in animation. The most basic production method is the use of stop-motion animation 
camera for filming tool, as the main object shoot a series of photos, each photo as a subject between for a small amount of movement, and finally the whole series of photos in quick succession to facilitate the completion broadcast. Easy to change because, plasticine stop-motion animation is the material used, the finished product is called clay animation. Stop-motion animation of the subject can be ever-changing, can be any object can be moved, including clay, cardboard or rubber, made into models or puppets, paper cutting, and other daily necessities as well as a real person, in addition can also be produced by way of painting.

Realistic style requirements in the design of the beginning of 1: time, place, space environment to be clear. 2: natural objects of the star features and texture features to be accurate. 3: the perspective of relations and rules to be accurate. 4: color relations and natural laws to be unified. 5: the law of the change of light and shadow should be harmonious and true ${ }^{[11-12]}$.

Cartoon style features: 1 , the shape of the exaggerated 2 , with fun, easy to accept 3 , color, highly summarized, simplistic, holistic Expressions for correlation:

$$
\text { Cor }=\frac{1}{\sigma_{x} \sigma_{y}} \sum_{i=0}^{L-1} \sum_{j=0}^{L-1}\left(i-\mu_{x}\right)\left(j-\mu_{y}\right) P_{i j}
$$

Comprehensive experimental style features: 1, highlighting the personality characteristics of the artist, the main body of 2, the pursuit of artistic taste, and stressed that the flowers and materials 3, a strong sense of the picture form, is not subject to the constraints of 4 , can be independent creation, investment is small ${ }^{[13]}$.

\section{ANIMATION SCENE PRODUCTION}

\section{A. principles of animation scene composition:}

\section{1) aesthetic principles}

Animation is an art, so it is the first to the composition of the United states. In other words, it is to have a visual sense of beauty, make people look comfortable, looks good. Animation computer scene distribution:

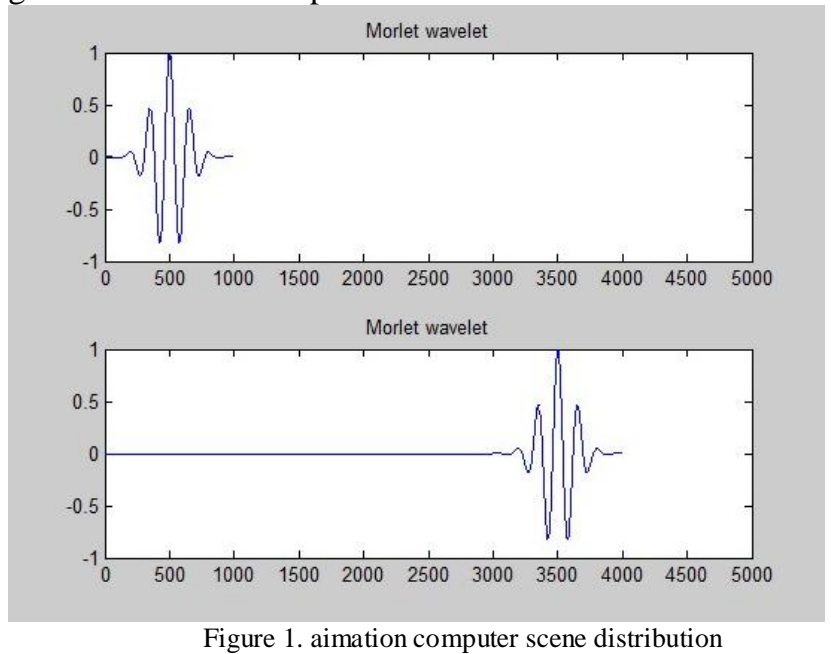

2) subject service principle

In a film, the composition of the painting is undoubtedly one of the forms of the film. And the theme of the film or story, is the film plays a decisive role in the content". Form must be content services, composition must also be the subject of service.

Headings, or heads, are organizational devices that guide the reader through your paper. There are two types: component heads and text heads.

Component heads identify the different components of your paper and are not topically subordinate to each other. Examples include Acknowledgments and References and, for these, the correct style to use is "Heading 5". Use "figure caption" for your Figure captions, and "table head" for your table title. Run-in heads, such as "Abstract", will require you to apply a style (in this case, italic) in addition to the style provided by the drop down menu to differentiate the head from the text.

Text heads organize the topics on a relational, hierarchical basis. For example, the paper title is the primary text head because all subsequent material relates and elaborates on this one topic. If there are two or more sub-topics, the next level head (uppercase Roman numerals) should be used and, conversely, if there are not at least two sub-topics, then no subheads should be introduced. Styles named "Heading 1", "Heading 2", "Heading 3", and "Heading 4" are prescribed.

\section{3) change principle}

Animation scene is not a photo. The audience can't stand a composition without changing the animation scene. And the change is also the main feature of the art of animation scenes and its charm lies. The change of a scene of animation can be described as the ever-changing, in addition to the composition of the contents of the changes in the form of a change in the form of composition is also an important change $\mathrm{e}^{[14]}$.

\section{B. animation scene color}

Different combinations of colors can produce different effects, different changes in the star animation scene. We can change things the sorrows and joys, scene objects through a combination of color and light weight, space and distance. In addition, the color changes in the scene can also reflect the role of the psychological and personality, to bring people to bring different psychological feelings, like a white symbol of purity and good, blue expression of the role of the authority and the conservative character, red color is the vitality, confidence, enthusiasm, representative.

According to the scene and characters of different requirements, reasonable use of color combination of complete different animation scene design, only the color to give humanity, in order to make the color in the animation scene with ease, the release of a color contains the unique charm.

\section{C. space shape of animation scene}

Space is formed between the form and the form, and the form of the object in the real world. The scene is not only the role of the role of the place, but also responsible for the entire animation of the movement. Animation scene can be divided into physical space and psychological space in space. In the animation scene, the physical space is the virtual reality space, which can be fully reproduced in the real world. It can also be created by the designers and the 
characters. And in the psychological space is the main role of the psychological world, designers need to have a deep understanding of the characters, combined with the elements of the animation scene design, design to meet the development of the plot, the characters of the characters design animation screen.

In the animation scene based on computer technology, the design of the space should include the following elements, line elements, shape elements, color elements, material elements, light and shadow elements. The line element and the shape factor is mainly responsible for the definition of the object and the background space in the scene, and the real space of the scene is formed by the combination of lines and shapes. The use of asymmetric shape factor will make the picture of the cartoon more abundant, make the content of the performance more prominent, more attractive to the audience's emotional and spiritual input. The color factor in the animation scene is attached to the object in the scene. When the picture in color and color fusion and collision, can actively mobilize the viewer's emotions, so that the audience mood and animation plot closely together. In these elements of the space of light and shadow factors and color factors are the same, the main role of light and shadow is used to render the animation space atmosphere, increase the atmosphere of animation, animation performance. In the process of defining the space, it is able to bring the attributes of the light and shadow to the scene, and the light and shadow elements also need to be expressed in the animated images of objects.

Space is formed between the form and the form, and the form of the object in the real world. The scene is not only the role of the role of the place, but also responsible for the entire animation of the movement. Animation scene can be divided into physical space and psychological space in space. In the animation scene, the physical space is the virtual reality space, which can be fully reproduced in the real world. It can also be created by the designers and the characters. And in the psychological space is the main role of the psychological world, designers need to have a deep understanding of the characters, combined with the elements of the animation scene design, design to meet the development of the plot, the characters of the characters design animation screen.

In the animation scene based on computer technology, the design of the space should include the following elements, line elements, shape elements, color elements, material elements, light and shadow elements. The line element and the shape factor is mainly responsible for the definition of the object and the background space in the scene, and the real space of the scene is formed by the combination of lines and shapes. The use of asymmetric shape factor will make the picture of the cartoon more abundant, make the content of the performance more prominent, more attractive to the audience's emotional and spiritual input. The color factor in the animation scene is attached to the object in the scene. When the picture in color and color fusion and collision, can actively mobilize the viewer's emotions, so that the audience mood and animation plot closely together. In these elements of the space of light and shadow factors and color factors are the same, the main role of light and shadow is used to render the animation space atmosphere, increase the atmosphere of animation, animation performance. In the process of defining the space, it is able to bring the attributes of the light and shadow to the scene, and the light and shadow elements also need to be expressed in the animated images of objects.

\section{SYSTEM ARCHITECTURE}

The information management system of digital library is designed by the way of centralized deployment, the database platform is designed, and the centralized deployment mode of the database is completely different from the way of integration. Integrated deployment refers to a set of database, the database needs to use the database to support and complete each other. The database set the deployment of the pointer to the corresponding deployment of each business system independent database, but the physical device uses the partition and other virtualization technology to achieve physical location.

Two kinds of database deployment plan can achieve the goal of the database, but the first way is more thorough database concentration, is achieved through the database application level, and the second way is through physical device virtual technology to achieve the database location integration.

SNA technology, which can meet the needs of data center's information storage, is the current widespread application of storage technology. According to the resource shared memory of the storage area, it can realize the effective collection of the storage resource, and make it more flexible when the storage resource is allocated to the virtual machine. Using centralized storage method to carry on the virtual device virtualization can make the resource management of the storage platform, improve the practicability and reliability.

\section{CONCLUSIONS}

Through the above introduction, we generally understand the development of China and the world of computer animation industry, to understand the main key technologies involved in the generation of computer animation scene, recognize the important position of the animation scene in the animation industry. Understand the achievements of a stunning animation works is a great project, a carefully conceived of the script, the role of designers, animation designers of hard exploration, but also the need to design and make the scene designer. The animation scene is an art which serves the film and television animation. In the process of animation scene design is the process of re understanding of the human space. It comes in human sense of space and form is the understanding and grasp of spatial dimension, the goal is passed through the animation to the audience be personally on the scene of the authenticity and integrity of feeling. 


\section{ACKNOWLEDGMENT}

A Project Supported by Scientific Research Fund of Hunan Provincial Education Department.

Project number: 14B143.

\section{REFERENCES}

[1] Zheng X, Cai Y. Energy-aware load dispatching in geographically located ineernet data centers[J]. Sustainable Computing: Informatics and Systems, 2011, 1(4):275-285.

[2] Breitgand D, Epstein A. Improving consolidation of virtual machines with risk-aware bandwidth oversubscription in compute clouds[C]. Proceedings of IEEE INFOCOM, 2012. 2861-2865.

[3] Zhang D, Guo D, Chen F, et al. TL-plane-based multi-core energy-efficient real-time scheduling algorithm for sporadic tasks[J]. ACM Trans. Archit. Code Optim, 2012,8(4):47-48.

[4] Chen Kang, Zheng Weimin, Cloud Computing: system examples and research status [J], software journal, 2009, 20 (5): 1337-1348.

[5] Yu L, Jiang T, Cao Y. Energy cost minimization for distributed internet data centers in smart microgrids considering power outages[J]. IEEE Trans. Parallel Distrib. Syst, 2015, 26(1):120-130.

[6] Glen E. Holt. Honest talk about finance in director recruitment[J]. The Bottom Line: Managing Library Finances,2006,192-196.
[7] Dimitrios Kondylis. Greek libraries' funding: a Greek tragedy with(out) euros and "katharsis" $[\mathrm{J}]$. The Bottom Line: Managing Library Finances, 2014,272-273.

[8] Garry D. Carnegie,Shannon Sidaway,Brian West. A Chaotic Field of Practice: Financial Reporting of the Library Collections of Australia's Public Universities, 2007-2011[J]. Australian Academic \&amp; Research Libraries, 2013,444-446.

[9] Ahmet Çelik. Financial Problems in University Libraries: the Turkish Case[J]. The International Information \&amp; Library Review,2000,321-323.

[10] Lauren Reiter. Financial Literacy and the Academic Library: Exploring the Peer-to-Peer Approach[J]. Journal of Business \&amp; Finance Librarianship,2015,201-203.

[11] Georgios Giannakopoulos,Alexandros Koulouris,Dionysis Kokkinos. Libraries in Crisis: A Glimpse over Greece an Cyprus[J]. Procedia - Social and Behavioral Sciences, 2014,147-148.

[12] L. I. Aleshin. Financial and technological bases as central factors in library informatization[J]. Scientific and Technical Information Processing,2012,391-393.

[13] AHMET ÇELIK. Financial Problems in University Libraries: the Turkish Case $[\mathrm{J}]$. International Information and Library Review,2000,321-325.

[14] Keller, Kit,LeBeau, Chris,Malafi, Elizabeth,Spackman, Andy. Meeting the Need for Library-based Financial Literacy Education[J]. Reference \&amp; User Services Quarterly,2015,543-545. 